\title{
Pemisahan anomali regional-residual data gayaberat daerah Karangsambung Jawa Tengah menggunakan metode tren surface analysis
}

\author{
Ledia Damayanti*, Oktaviana, Ahmad Al Farizi, Ilham Dani, dan Syamsurijal Resimeng \\ Jurusan Teknik Geofisika, Fakultas Teknik, Universitas Lampung \\ Jl. Prof. Dr. Ir. Sumantri Brojonegoro, Gedong Meneng, Kec. Rajabasa, Kota Bandar Lampung, Lampung \\ *email: ledia.pangestu@gmail.com
}

\begin{abstract}
Abstrak - Pemisahan anomali regional-residual pada metode gravitasi di daerah Karang Sambung Jawa Tengah menggunakan metode tren surface analysis. Pemisahan anomali ini dibuat dengan menggunakan bahasa program Matlab dan kemudian dibuat penampangnya menggunakan software Surfer. Interpretasi kualitatif dilakukan dengan mengamati data gayaberat berupa anomali Bouguer. Sedangkan Interpretasi kuantitatif dilakukan untuk memahami lebih dalam hasil interpretasi kualitatif dengan membuat penampang gayaberat pada peta kontur anomali. Berdasarkan hasil analisis spektrum hasil penapisan dengan lebar jendela $23 \times 23 \mathrm{~km}$ didapatkan peta anomali regional. Nilai anomali residual yang didapat berkisar antara -45 sampai $30 \mathrm{mGal}$ yang menunjukkan pola anomali negatif hingga positif. Anomali negatif berkisar antara -45 sampai $-10 \mathrm{mGal}$, sedangkan anomali positif berkisar antara 0 sampai $30 \mathrm{mGal}$. .
\end{abstract}

Kata kunci: Metode gravitasi, pemisahan anomali regional-residual, tren surface analysis

Abstract - Separation of regional-residual anomalies in the gravity method in the Karang Connect area of West Java using the surface analysis trend method. The separation of this area is made using the Matlab program language and then made its appearance in the Surfer software. Qualitative interpretation is done by observing gravity data in the form of Bouguer anomalies. Whereas quantitative interpretation is carried out to understand deeper the results of qualitative interpretation by making a cross section of gravity on the anomaly contour map. Based on the results of spectrum analysis results of screening with a window width of $23 \times 23 \mathrm{~km}, \mathrm{a}$ regional anomaly map was obtained. Residual anomaly values otained ranged from -45 to $30 \mathrm{mGal}$ which showed a negative to positive anomaly pattern. Negative anomalies are range of -45 to $-10 \mathrm{mGal}$, while positive anomalies are range of 0 to $30 \mathrm{mGal}$.

Key words: Gravity method, Separation Regional-Residual Anomaly, tren surface analysis.

\section{PENDAHULUAN}

Metode gayaberat adalah salah satu metode geofisika yang didasarkan pada pengukuran medan gravitasi. Pengukuran ini dapat dilakukan di permukaan bumi, di kapal maupun di udara. Prinsip metode ini mempunyai kemampuan dalam membedakan rapat massa suatu material terhadap lingkungan sekitarnya. Dengan demikian struktur bawah permukaan dapat diketahui. Pada dasarnya gravitasi adalah gaya tarik menarik antara dua benda yang memiliki rapat massa yang berbeda, hal ini dapat diekspresikan oleh rumus hukum Newton.

Pengolahan data metode gravitasi secara umum dipisahkan menjadi dua macam, yaitu proses dasar dan proses lanjutan. Proses dasar mencakup seluruh proses berawal dari nilai pembacaan alat di lapangan sampai memperoleh nilai anomali Bouguer di setiap titik pengamatan. Penggunaan metode gaya berat untuk eksplorasi sumber daya alam, studi keilmuan dan maksud lainnya dilakukan dengan menerapkan konsep anomali gaya berat (anomali Bouguer). Perbedaan nilai gaya berat terukur dengan nilai gaya berat acuan, yaitu nilai gaya berat teoritis untuk suatu model teoritis Bumi (Spheroid, Geoid). Perbedaan tersebut merefleksikan variasi rapat massa yang terdapat pada suatu daerah dengan daerah sekelilingnya ke arah lateral, maupun ke arah vertikal.Anomali Bouguer merupakan penjumlahan dari anomali regional dan anomali residual. Biasanya anomali bouguer masih mengandung beberapa anomali dari berbagai sumber. Anomali dengan panjang gelombang besar yang berasal dari kontras densitas dalam disebut anomali regional. Hal ini sangat penting untuk memahami struktur dengan skala besar dari lapisan bumi seperti zona subduksi. Sedangkan anomali dengan panjang gelombang rendah yang berasal dari anomali massa di sekitar daerah eksplorasi disebut anomali 
residual. Pemisahan anomali regional dan residual sangat penting dalam tahap interpretasi peta kontur gravitasi. Salah satu cara pemisahan anomali adalah menggunakan metode tren surface analysis.

\section{LANDASAN TEORI}

Metode gayaberat umumnya digunakan dalam eksplorasi jebakan minyak (oil trap). Disamping itu metode ini juga banyak dipakai dalam eksplorasi mineral dan lainnya (Kearey dkk., 2002).Prinsip pada metode ini mempunyai kemampuan dalam membedakan rapat massa suatu material terhadap lingkungan sekitarnya. Dengan demikian struktur bawah permukaan dapat diketahui. Untuk menggunakan metode ini dibutuhkan minimal dua alat gravitasi, alat gravitasi yang pertama berada di base sebagai alat yang digunakan untuk mengukur pasang surut gravitasi, alat yang kedua dibawa pergi ke setiap titik pada stasiun mencatat perubahan gravitasi yang ada. Biasanya dalam pengerjaan pengukuran gravitasi ini, dilakukan secara looping (Supriyadi, 2009).

Pada dasarnya gravitasi adalah gaya tarik menarik antara dua benda yang memiliki rapat massa yang berbeda, hal ini dapat diekspresikan oleh rumus hukum Newton sederhana sebagai berikut:

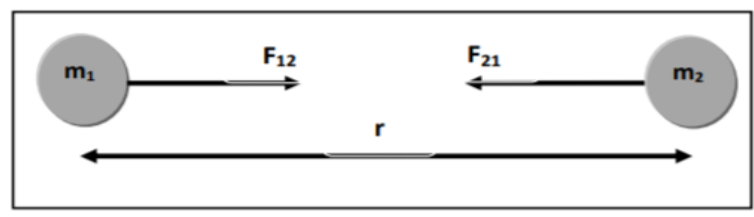

Gambar 1. Gaya tarik menarik antara dua benda

$$
F=G \frac{m_{1} m_{2}}{r^{2}}
$$

Di mana $F$ gaya tarik menarik, $G$ konstanta universal gayaberat $\left(6,67 \times 10-11 \mathrm{~m}^{3} \mathrm{~kg}^{-1} \mathrm{~s}^{-2}\right), m_{1}$ dan $m_{2}$ massa benda, dan $r$ jarak antar pusat massa.)

Nilai gravitasi bergantung kepada lima faktor, yaitu lintang, elevasi topografi daerah sekitar pengukuran, pasang surut bumi, dan variasi densitas di bawah permukaan [1]. Koreksi dalam metode gravitasi diperlukan untuk menghilangkan faktor-faktor lain yang mempengaruhi besar nilai gravitasi sehingga didapatkan nilai gravitasi yang hanya disebabkan oleh pengaruh variasi densitas di bawah permukaan. Berikut adalah koreksikoreksi yang dilakukan kepada data gravitasi lapangan $\left(\mathrm{g}_{\text {read }}\right)$ :

\section{Koreksi Pasang Surut (Tide Correction)}

Koreksi ini dilakukan untuk menghilangkan pengaruh gravitasi benda-benda di luar bumi seperti bulan dan matahari, yang berubah terhadap lintang dan waktu. Dalam prakteknya, koreksi tidal dilakukan dengan cara mengukur nilai gayaberat di stasiun yang sama (base) pada interval waktu tertentu. Nilai koreksi tidal ini selalu ditambahkan pada pembacaan gayaberat.

$$
g_{t}=g_{o b s}+\text { Tide } e_{o b s}
$$

di mana: $g_{\mathrm{t}}$ gayaberat terkoreksi tidal, $g_{\text {obs }}$ gayaberat bacaan, tide obs koreksi tidal

\section{Koreksi Apungan (Drift Correction)}

Koreksi apungan akibat adanya perbedaan pembacaan gayaberat dari stasiun yang sama pada waktu yang berbeda, yang disebabkan karena adanya guncangan pegas alat gravimeter selama proses transportasi dari suatu stasiun ke stasiun lainnya. Untuk menghilangkan efek ini, akuisisi data gayaberat didesain dalam suatu rangkaian tertutup (loop), sehingga besar penyimpangan tersebut dapat diketahui dan diasumsikan linier pada selang waktu tertentu. Koreksi drift pada masing-masing titik stasiun adalah:

$$
\operatorname{drift} \mathrm{t}_{\mathrm{n}}=\frac{t_{n}-\mathrm{t}_{1}}{t_{N}-t_{1}}\left(g_{N}-g_{1}\right)
$$

di mana $t_{n}$ waktu pembacaan pada stasiun ke- $n, t_{1}$ waktu pembacaan pada stasiun base (awal looping), $t_{N}$ waktu pembacaan pada stasiun base (akhir looping), $g_{1}$ bacaan gravimeter terkoreksi tidal pada stasiun base (awal looping), $g_{N}$ bacaan gravimeter terkoreksi tidal pada stasiun base (akhir looping), dan $g_{\text {lokal }}$ gayaberat terkoreksi driftdan tidal

\section{Koreksi Lintang}

Koreksi ini dilakukan karena bentuk bumi yang tidak sepenuhnya bulat sempurna, sehingga terdapat perbedaan antara jari-jari bumi di kutub dengan di daerah katulistiwa sebesar $21 \mathrm{~km}$. Dengan demikian nilai gayaberat di kutub akan lebih besar dibandingkan nilai gayaberat di katulistiwa. Secara umum gravitasi terkoreksi lintang dapat ditulis sebagai berikut :

$$
g \varphi=978031,8\left(1+5,3024 \cdot 10^{-3} \sin ^{2} \varphi-5,8 \cdot 10^{-6} \sin ^{2} 2 \varphi\right.
$$

\section{Koreksi Bouguer}

Koreksi bouger merupakan koreksi ketinggian yang memperhitungkan adanya efek dari massa batuan yang berada di antara bidang datum 
(geoid) dan titik amat dengan asumsi memiliki jari-jari tak terhingga dengan tebal $\mathrm{h}$ (meter) dan densitas $\rho\left(\mathrm{gr} / \mathrm{cm}^{3}\right)$. Sehingga koreksi ini dapat ditulis sebagai berikut:

$$
B C=0,0419 . \rho . h . \mathrm{mGal}
$$

di mana $\rho$ rapat massa rata-rata daerah penelitian $\left(\mathrm{gr} / \mathrm{cm}^{3}\right), h$ ketinggian titik amat (m)

Analisis spektrum dilakukan untuk mengestimasi lebar jendela dan mengestimasi kedalaman dari anomali gayaberat. Selain itu analisis spektrum juga dapat digunakan untuk membandingkan respon spektrum dari berbagai metode filtering. Analisisi spektrum dilakukan dengan mentransformasi fourier lintasanlintasan yang telah ditentukan. Spektrum diturunkan dari potensial gayaberat yang teramati pada suatu bidang horizontal dimana transformasi fouriernya sebagai berikut [2].

$$
\begin{aligned}
& F(U)=\gamma \mu F\left(\frac{1}{r}\right) \text { dan } \\
& F\left(\frac{1}{r}\right)=2 \pi \frac{e^{|x|\left(z_{0}-z_{f}\right)}}{|k|}
\end{aligned}
$$

maka persamaannya menjadi

$$
F(U)=2 \pi \gamma \frac{e^{|x|\left(z_{0}-z_{f}\right)}}{|k|}
$$

di mana $U$ potensial gayaberat $\mu$ anomali rapat massa, $\gamma$ konstanta gayaberat, $r$ jarak.

Nilai Anomali Baouguer yang terukur di permukaan merupakan gabungan dari beberapa sumber anomali dan struktur. Sehingga perlu dilakukan pemisahan anomali untuk memperoleh anomali target yang akan dicari. Metode tren surface analysis merupakan salah satu cara untuk memisahkan anomali regional, residual dan noise.

\section{METODE PENELITIAN}

Penelitian ini berada pada daerah Karangsambung Jawa Tengah. Obyek penelitian ini adalah pemisahan anomali regional-residual pada penelitian metode gravitasi. Pada penelitian ini akan dibuat program komputer menggunakan MATLAB dan kemudian dibuat penampangnya menggunakan software Surfer. Tahapan pertama yang dilakukan dalam penelitian adalah pengumpulan data hasil akuisisi, yaitu data hasil pengukuran gayaberat berupa koordinat $X, Y$ dan anomali bouguer lengkap. Tahapan kedua merupakan tahapan pengolahan data yang ditekankan dalam penelitian ini, terdiri dari slicing/digitizing, transformasi Fourier, dan analisis spektrum. Tahapan ketiga merupakan pengolahan data lanjut yang terdiri dari Metode tren surface analysis yang merupakan metode dengan pendekatan polynomial terhadap data-data anomali bouguer yang akan diolah. TSA menggunakan prinsip dasar persamaan berikut:

$$
\begin{aligned}
& g(x, y)=c_{1} x_{i}^{0} y_{i}^{0}+c_{2} x_{i}^{l} y_{i}^{0}+c_{3} x_{i}^{0} y_{i}^{l}+\cdots+c_{n+1} x_{i}^{n} y_{i}^{n} \\
& g(x, y)=\sum_{k=1}^{N} \sum_{j=1}^{M} x_{i}^{j-1} y_{i}^{k} c_{j}
\end{aligned}
$$

di mana $i$ adalah $1,2,3, \ldots \ldots$, n.

Dari persamaan tersebut akan dihitung nilai anomali dengan menggunakan orde 1 , orde 2 sampai dengan orde 3 . Kemudian setelah didapatkan nilai anomali regionalnya dapat dihitung anomali residual.

\section{HASIL DAN PEMBAHASAN}

Proses pemisahan daerah anomali regionalresidual dilakukan dengan menggunakan metode polynomial tren surface analysis. Interpretasi gayaberat secara umum dibedakan menjadi dua yaitu interpretasi kualitatif dan kuantitatif. Interpretasi kualitatif dilakukan dengan mengamati data gayaberat berupa anomali Bouguer. Anomali tersebut akan memberikan hasil secara global yang masih mempunyai anomali regional dan residual. Dengan interpretasi ini dapat dilihat arah penyebaran anomali. Interpretasi kuantitatif dilakukan untuk memahami lebih dalam hasil interpretasi kualitatif dengan membuat penampang gayaberat pada peta kontur anomali. Teknik interpretasi kuantitatif mengasumsikan distribusi rapat-massa dan menghitung efek gayaberat yang diamati. Interpretasi kuantitatif pada penelitian ini adalah analisis tren surface.

\section{Analisis Peta Anomali Bouguer Lengkap (ABL)}

Setelah melalui proses reduksi lalu digambarkan dalam bentuk peta anomali bouguer lengkap (ABL) sebagai berikut: 


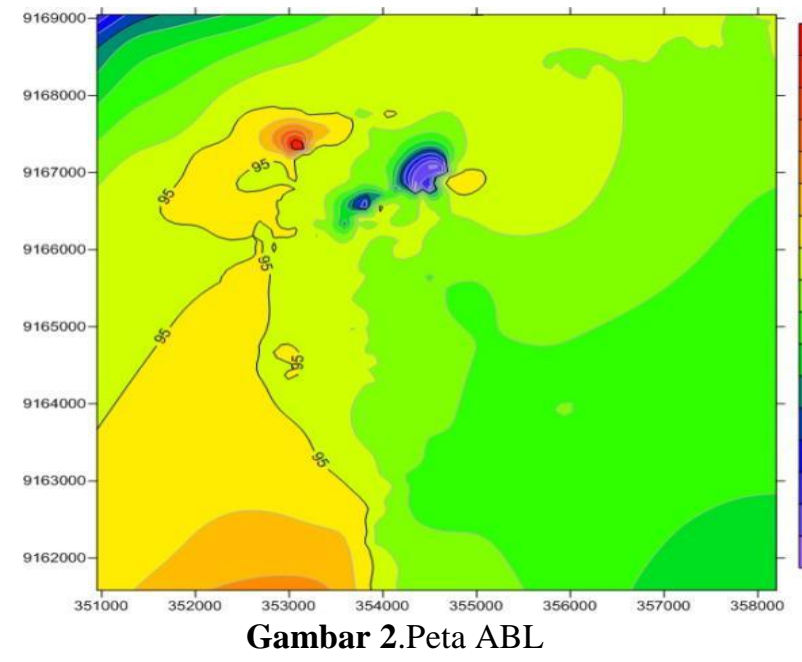

Pada peta ABL dapat dilihat bahwa memiliki rentang nilai anomali bouguer di daerah penelitian berkisar 45 hingga $125 \mathrm{mGal}$. Anomali rendah tersebar pada bagian barat laut dan utara tengah peta, anomali sedang tersebar pada timur dan selatan peta, dan anomali tinggi tersebar pada bagian barat daya dan utara peta. Perubahan dari anomali tersebut, tampak jelas adanya perubahan nilai anomali rendah ke tinggi yang cukup signifikan. Hal ini disebabkan oleh perubahan nilai kontras rapat-massa batuan yang terjadi pada daerah penelitian.

\section{Pemisahan Anomali Regional-Residual}

Anomali regional dan residual diperoleh dari nilai Anomali Bouguer Lengkap (ABL). Anomali Bouguer yang terbaca masih dipengaruhi oleh nilai anomali dalam dan anomali dangkal. Anomali Bouguer yang telah dikoreksi tersebut merupakan respon anomali yang berasal dari material bawah permukaan.

\section{Peta Anomali Regional}

Berdasarkan hasil analisis spektrum dengan lebar jendela $23 \times 23 \mathrm{~km}$ didapatkan peta anomali regional. Kedalaman regional ini mengindikasikan bahwa kedalaman kerak bawah hingga basement pada daerah penelitian.

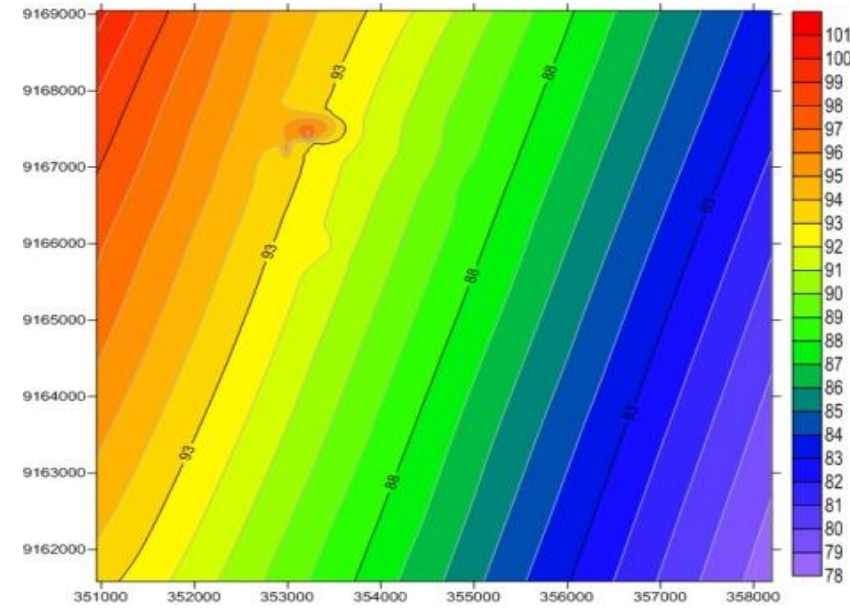

Gambar 3. Peta Anomali regional orde 1

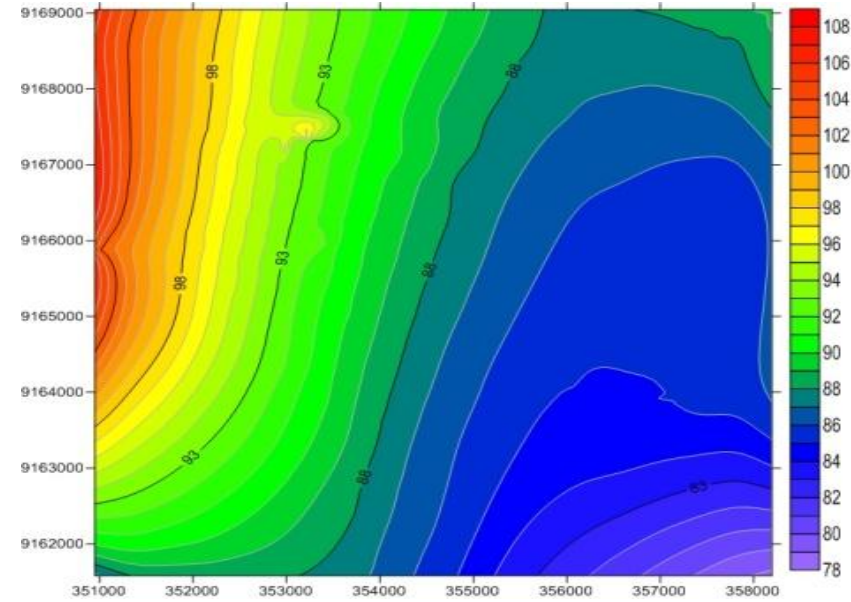

Gambar 4. Peta Anomali regional orde 2

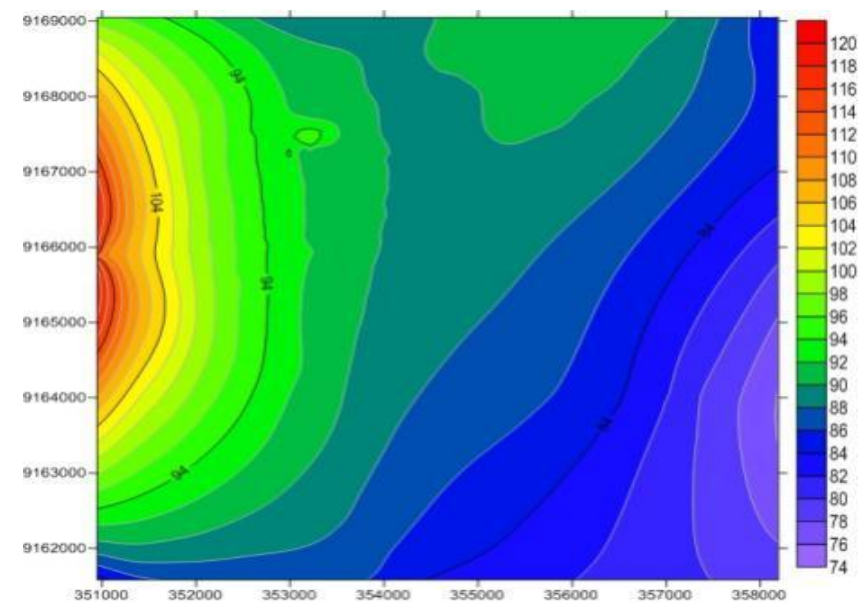

Gambar 5. Peta anomali regional orde 3

Peta anomali regional yang didapatkan menggunakan polynomial orde satu menghasilkan nilai anomali sebesar 78-101 mGal, orde dua menghasilkan nilai anomali 78$108 \mathrm{mGal}$, dan orde tiga menghasilkan nilai anomali 74-120 mGal. Perubahan nilai ini disebabkan adanya kontras rapat massa batuan 
yang besar di sekitar rapat kontur ini yang kemungkinan merupakan daerah sesar.

\section{Peta Anomali Residual}

Peta anomali residual ini menunjukkan sumber anomali yang bersifat lokal, biasanya berasosiasi dengan cekungan Tersier (mengindikasikan letak top basement dengan sedimennya)

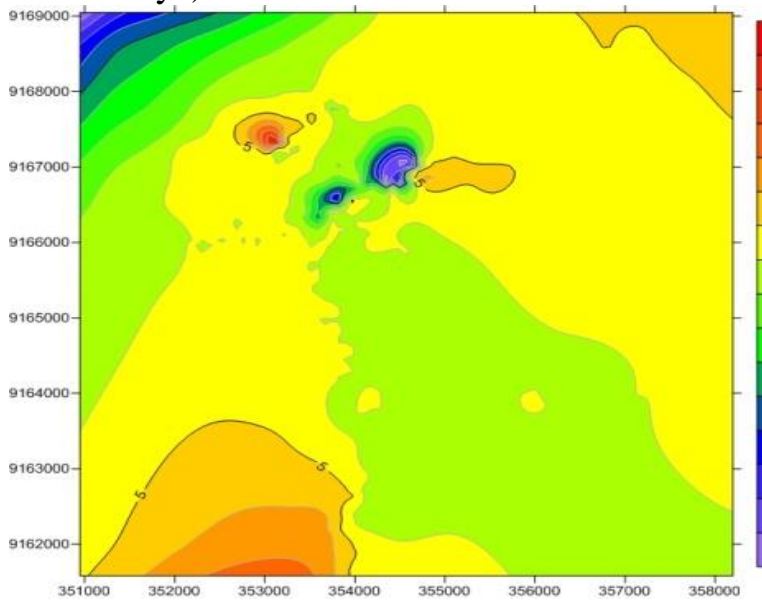

Gambar 6. Peta anomali regional orde 1

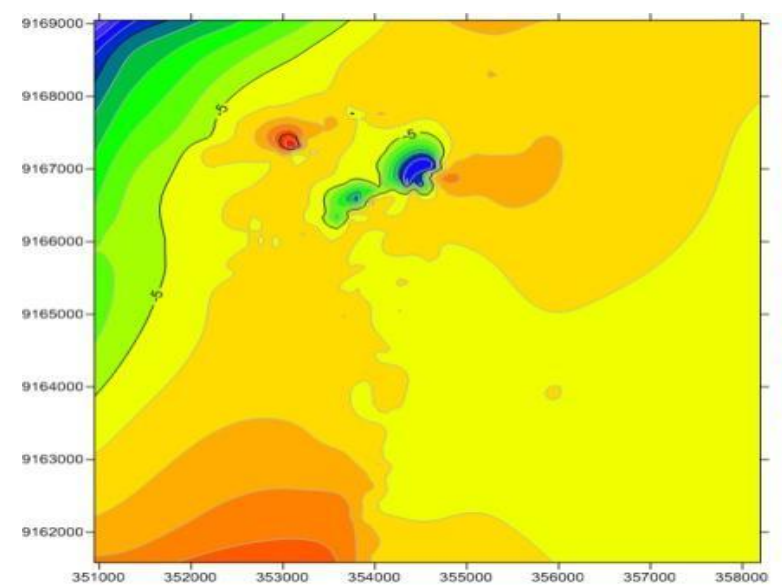

Gambar 7.Peta anomali residual orde 2

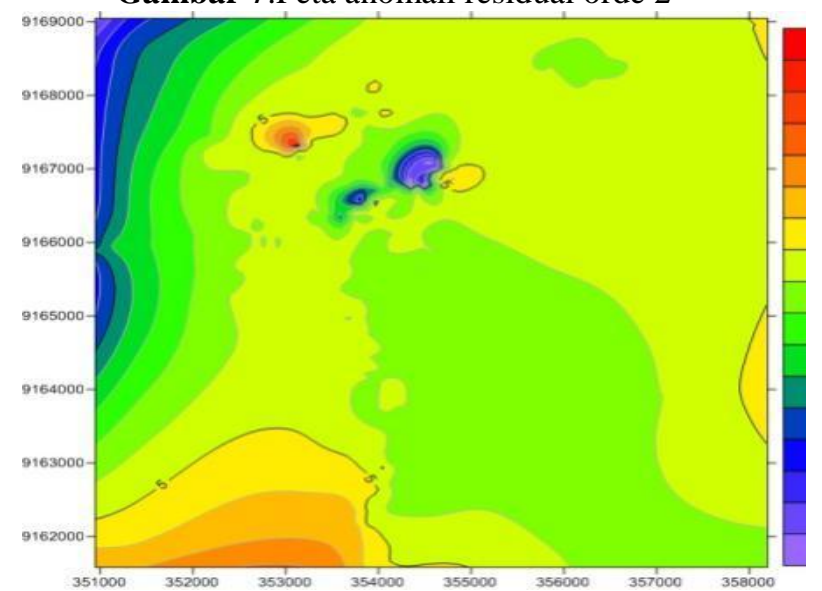

Gambar 8. Peta anomali residual orde 3
Nilai anomali residual yang didapat berkisar antara -45 sampai $30 \mathrm{mGal}$ yang menunjukkan pola anomali negatif hingga positif. Anomali negatif bernilai -45 sampai -10 mGal, sedangkan anomali positif bernilai 0 sampai 30 mGal. Dari peta residual dapat dilihat adanya anomali tinggi serta pola kontur yang diinterpretasikan sebagai intrusi. Berdasarkan peta geologi regional diduga salah satunya merupakan intrusi dangkal.

\section{KESIMPULAN}

Sistem deteksi kemiringan gedung bertingkat dapat dibuat menggunakan resistor variabel yang dipasang bandul sebagai sensor dengan karakteristik sebagai berikut:

\begin{tabular}{|c|c|c|c|c|c|}
\hline $\begin{array}{c}\text { Akurasi } \\
(\%)\end{array}$ & $\begin{array}{c}\text { Presisi } \\
(\%)\end{array}$ & $\begin{array}{c}\text { Eror } \\
(\%)\end{array}$ & $\begin{array}{c}\text { Waktu } \\
\text { respon }(\mathrm{s})\end{array}$ & \multicolumn{2}{|c|}{$\begin{array}{c}\text { Sistem } \\
\text { peringatan }\end{array}$} \\
\cline { 5 - 6 } & & & & $<1,5^{\circ}$ & $\geq 1,5^{\circ}$ \\
\hline 89,34 & 91,07 & $\begin{array}{c}10,6 \\
6\end{array}$ & 4,13 & 0 & 1 \\
\hline
\end{tabular}

\section{UCAPAN TERIMA KASIH}

Berdasarkan data Gayaberat Daerah Karang Sambung Jawa Tengah dari hasil filtering dengan menggunakan polynomial orde satu menghasilkan nilai anomali sebesar 78-101 mGal, orde dua menghasilkan nilai anomali 78$108 \mathrm{mGal}$, dan orde tiga menghasilkan nilai anomali 74-120 mGal. Perubahan nilai ini disebabkan adanya kontras rapat massa batuan yang besar di sekitar rapat kontur ini yang kemungkinan merupakan daerah sesar. Sedangkan Nilai anomali residual yang didapat berkisar antara -45 sampai $30 \mathrm{mGal}$. Dari peta residual dapat dilihat adanya anomali tinggi serta pola kontur yang diinterpretasikan sebagai intrusi.

\section{PUSTAKA}

[1] Telford, WM. Applied Geophysics Second Edition. Cambridge University, 1990.

[2] Blakely, R.J., Potential Theory In Gravity and Magnetic Applications, Cambridge University Press, Cambridge, 1995.

[3] Kearey, P., An Introduction to Geophysical Exploration 3rd Edition. Blackwell ltd. London, 2002.

[4] Supriyadi, Studi Gaya Berat Relatif Di Semarang. Jurnal Pendidikan Fisika Indonesia, 5(1) 2009. 